\title{
STUDY ON PREPARATION AND PROPERTIES OF PHENOL-FORMALDEHYDE-CHINESE FIR LIQUEFACTION COPOLYMER RESIN
}

\author{
Ruihang Lin', Jin Sun', Chao Yue ${ }^{3}$, Xiaobo Wang ${ }^{3}$, Dengyu Tu ${ }^{1}$, Zhenzhong Gao ${ }^{1, \$}$
}

In memoriam of Dr. Manfred SCHWANNINGER

\begin{abstract}
A new zero-waste and zero-pollution composite adhesive labeled Chinese fir-based adhesive for exterior plywood was synthesized by blending alkaline Chinese fir (Cunninghamia lanceolata) liquid with a small amount of phenol-formaldehyde (PF). The free phenol and free formaldehyde content of the Chinese fir-based adhesive were sharply decreased compared to normal PF resin by more than $50 \%$. The synthetic adhesive show with excellent water resistance and environmental friendliness, which had a $28 \mathrm{~h}$ boil-dry-boil wet bonding strength of 1,73MPa according to standard JIS K6806-2003 and a formaldehyde emission of $0,045 \mathrm{mg} / \mathrm{L}$ according to standard JIS A1460-2003. The structural properties and their thermal properties of cured adhesives were evaluated using Fourier transform infrared (FT-IR) and differential scanning calorimetry (DSC). The FT-IR analysis confirmed the expected chemical structure as the Chinese fir liquid reacted with formaldehyde and phenol which occurred at the wavenumbers of $1733,1698,1652 \mathrm{~cm}^{-1}$ and $1077,1048 \mathrm{~cm}^{-1}$. Although the DSC results indicated that the Chinese firbased adhesive's curing need higher temperature than the control PF resin, the higher curing temperature hardly cripple the availability of Chinese fir-based resin in the plywood production.
\end{abstract}

Keywords: Chinese fir-based adhesive, formaldehyde, bonding properties, FT-IR, DSC.

\section{INTRODUCTION}

The petrochemical-based phenol-formaldehyde adhesives, have commonly been used in the production of wood-based panels (Yang et al. 2009). However, the declining fossil fuel reserves combined with the increasing price of fossil fuel have become a barrier of wood composite boards (Klaas et al. 2009). Therefore, more and more exploitations aimed at applying natural and economical products as substitutes for conventional wood resin adhesives. In recent years, there have been many attempts to replace petrochemicals with renewable resources, such as lignin (Kouisni et al. 2011), cornstarch (Moubarik et al. 2009), tannin (Bisanda et al. 2003), protein (Wang et al. 2012), cashew nut shell (Papadopoulou and Chrissafis 2011), wheat straw (Chen et al. 2012) for wood resin adhesives. However, few of them can be further applied for industrial processes due to their inherent disadvantages in compromised adhesive strength, low water-resistance or high formaldehyde emission.

Wood, the most abundant biomass in nature, has been regarded as the most promising renewable resource. It is a complex bio-composite mainly consisting of three structural components: cellulose, hemicellulose and lignin (Binder et al. 2009) Lignin is of particular interest because of its phenolic formation from which a wide variety of phenols and phenol derivatives and aromatic chemicals can be derived. Cellulose and hemicellulose can be converted into polyols, aldehydes and other small molecule compounds under certain conditions (Liu et al. 2012). Hence, considerable attention has been given to the preparation of environmentally friendly polymeric products from liquefied woods and their derivatives.

\footnotetext{
'Department of Wood Science and Engineering, College of Forestry, South China Agricultural University, Wushan Road, Tianhe, Guangzhou, Guangdong, P.R of China, 510642

${ }^{2}$ Liming Research Institute of Chemical Industry, Wangcheng Road, Xigong, Luoyang, Henan, P.R of China, 471001

${ }^{3}$ Guangdong Monitoring Station for Quality Supervision and Testing of Wood \& Wood Products, Wushan Road, Tianhe, Guangzhou, Guangdong, P.R of China, 510642

Corresponding author: zzgao@scau.edu.cn

Received:15.05. 2013 Accepted: 15.07.2013
} 
Until now, there were two main methods of wood liquefaction. The first liquefaction method is called phenolysis, involving phenol with acids as catalysts, which resulted in liquefaction products rich in combined phenolic compounds. Further application in the preparation of phenolic adhesives is similar to the conventional phenol resins (Wang et al. 2009), mouldings (Lee et al. 2011) and others. The second method was achieved in existence of alcohols, especially polyhydric alcohols, and the resulting products can be used as polyols for the preparation of polyurethane and epoxy products (Hajime et al. 2011, Niu et al. 2011). However, some research on the liquefaction of wood in alkaline medium show enormous potential (Yin et al. 2010, Moubarik et al. 2009). All of them reveal that alkaline treatment at elevated temperature is used to enhance the reactivity of the crystalline cellulose through decreasing DP (degrees of polymerization) and increasing accessibility of cellulose. Meanwhile, the lignin components depolymerize to form monomeric and oligomeric phenolic compounds. Therefore, liquefaction of wood combined with alkaline catalysts under high temperature appears to be an attractive way to obtain low molecular weight compounds in the further use.

The production of Chinese fir, which provides woody residues from furniture manufacturing, is increasing annually in South China. Only little of it is consumed in traditional applications such as using as an industrial fuel for boilers or as raw materials for particle boards. However, most of the residues are discarded and disposed of by burning in open fields. It is therefore worthwhile to develop potential uses for such residues. In this study, we evaluated the huge potential of waste Chinese fir as a biomass resource for the production of adhesives. In order to obtain a Chinese fir-based adhesive of desirable properties for bonding plywood in exterior use, the Chinese fir powder was liquefied in sodium hydroxide solution at $200^{\circ} \mathrm{C}$ for pretreatment, then co-polymerized with phenol-formaldehyde to synthesize biomass adhesive. The Chinese fir-based adhesives were formulated with high percents of Chinese fir liquefied resulting in the adhesive formulations that reduce the petrochemical dependency of conventional wood adhesives.

\section{MATERIALS AND METHODS}

\section{Materials}

Cunninghamia lanceolata Hook (collected in Guangdong Province, China) was ground into powder in a rotating disintegrator. The wood powder with a dimension passing 100 mesh was dehydrated in an oven at $105^{\circ} \mathrm{C}$ until oven-dried. Reagent grade phenol and formaldehyde (formalin, at concentration of 37\%) solution were purchased from Guangdong Guanghua Chemical Factory Co. Ltd, China. Other analytical chemicals such as sodium hydroxide $(\mathrm{NaOH})$, hydrochloric acid $(\mathrm{HCl})$, sodium thiosulfate pentahydrate $\left(\mathrm{Na}_{2} \mathrm{~S}_{2} \mathrm{O}_{3} \cdot 5 \mathrm{H}_{2} \mathrm{O}\right)$, absolute ethyl alcohol $\left(\mathrm{C}_{2} \mathrm{H}_{5} \mathrm{OH}\right)$, potassium iodide $(\mathrm{KI})$, iodine $\left(\mathrm{I}_{2}\right)$, hydrochloric acid $\left(\mathrm{HONH}{ }_{3} \mathrm{Cl}\right)$, ammonium acetate $\left(\mathrm{CH}_{3} \mathrm{COONH}_{4}\right)$, acetylacetone $\left(\mathrm{CH}_{3} \mathrm{COCH}_{2} \mathrm{COCH}_{3}\right)$ were obtained from Guangzhou chemical reagent factory, China.

\section{Liquefaction of Chinese fir powder}

The Chinese fir powder was liquefied in sealed reactor using a stainless steel autoclave reactor under the following conditions: column, $12 \mathrm{~cm} \times 12 \mathrm{~cm} \times 1,5 \mathrm{~cm}$ (diameter $\times$ height $\times$ thickness); limit temperature, $500^{\circ} \mathrm{C}$; limit pressure, $12 \mathrm{MPa}$ (figure 1 ). About $75 \mathrm{~g}$ Chinese fir powder was loaded into the reactor. A concentration of $25 \%$ sodium hydroxide solution ( $300 \mathrm{~g}$ in total) was gradually charged into the reactor with stirring. After all of the sodium hydroxide solution had been loaded, the reactor was sealed, and the mixture was kept in oil bath at $200 \pm 2^{\circ} \mathrm{C}$ for $15 \mathrm{~min}$. The liquefied resultant was cooled and preserved for synthesis. The residue rate of the liquefied product was only $0,65 \mathrm{wt} \%$ (base on the total mass of the final liquefaction), so it did not need to be filtered and can be used to synthetize directly. 


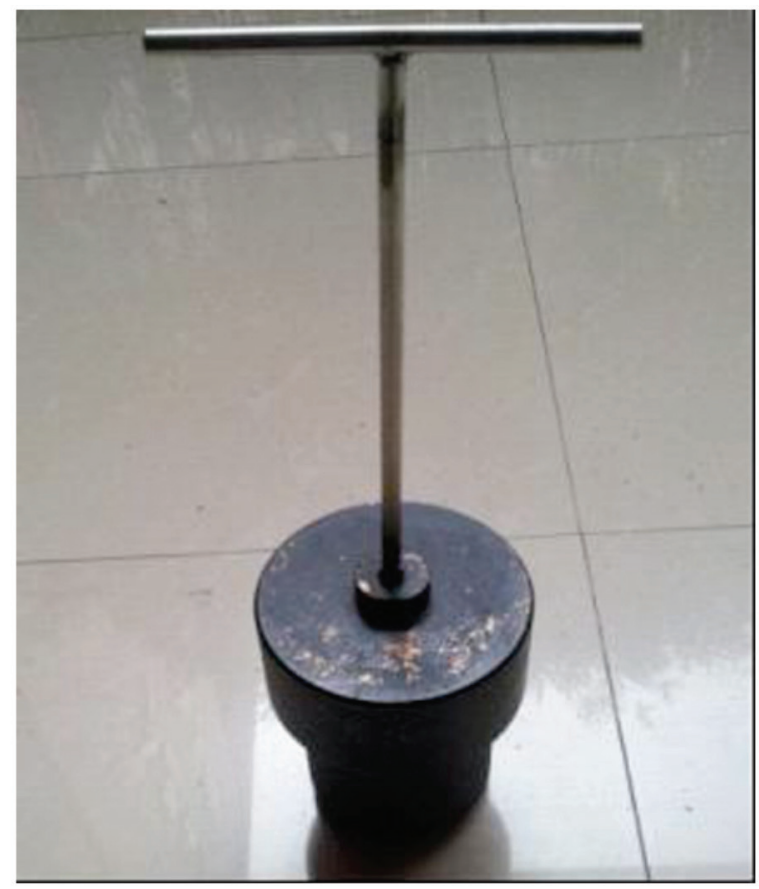

Figure 1. Liquefaction reactor.

\section{Preparation of Chinese fir-based adhesives}

For preparing Chinese fir-based adhesives, the Chinese fir liquid was used to prepare resins in the reaction flask. The three weight ratios of Chinese fir (CF) liquid to phenol-formaldehyde (PF) (60/40, 55/45 and 50/50), three molar ratio of formaldehyde to phenol (the values are 2:1, 2,5:1 and 3:1) were chosen respectively as the variables. The typical synthesis procedure was described as below in which the $\mathrm{PF} / \mathrm{CF}$ was $60 / 40$ with molar ratio of $2: 1$. The preparation conditions of all adhesives are summarized in table 1. 
Table 1. Preparation conditions of Chinese fir-based adhesives and control PF adhesives.

\begin{tabular}{|c|c|c|c|c|c|c|}
\hline Adhesive ID & $\begin{array}{l}\text { Chinese fir } \\
\text { liquid }(\mathrm{g})\end{array}$ & $\begin{array}{l}\text { Phenol } \\
\text { (g) }\end{array}$ & $\begin{array}{c}37 \% \\
\text { Formaldehyde (g) }\end{array}$ & $\begin{array}{l}50 \% \mathrm{NaOH} \\
\text { solution }(\mathrm{g})\end{array}$ & $\mathrm{CF} / \mathrm{PF}$ & $\mathrm{F} / \mathrm{P}$ \\
\hline $60 / 40-2: 1$ & 160,50 & 47,00 & 60,00 & 1 & $60 / 40$ & $2: 1$ \\
\hline $55 / 45-2: 1$ & 130,78 & 47,00 & 60,00 & I & $55 / 45$ & $2: 1$ \\
\hline $50 / 50-2: 1$ & 107,00 & 47,00 & 60,00 & 1 & $50 / 50$ & $2: 1$ \\
\hline $60 / 40-2,5: 1$ & 183,00 & 47,00 & 75,00 & I & $60 / 40$ & $2,5: 1$ \\
\hline $55 / 45-2,5: 1$ & 149,11 & 47,00 & 75,00 & I & $55 / 45$ & $2,5: 1$ \\
\hline $50 / 50-2,5: 1$ & 122,00 & 47,00 & 75,00 & 1 & $50 / 50$ & $2,5: 1$ \\
\hline $60 / 40-3: 1$ & 205,50 & 47,00 & 90,00 & I & $60 / 40$ & $3: 1$ \\
\hline $55 / 45-3: 1$ & 167,44 & 47,00 & 90,00 & I & $55 / 45$ & $3: 1$ \\
\hline $50 / 50-3: 1$ & 137,00 & 47,00 & 90,00 & 1 & $50 / 50$ & $3: 1$ \\
\hline $2: 1$ & 1 & 47,00 & 60,00 & 21,40 & 1 & $2: 1$ \\
\hline $2,5: 1$ & I & 47,00 & 75,00 & 24,40 & 1 & $2,5: 1$ \\
\hline $3: 1$ & I & 47,00 & 90,00 & 27,40 & I & $3: 1$ \\
\hline
\end{tabular}

$47 \mathrm{~g}$ of phenol and $60 \mathrm{~g}$ of formalin (the F/P molar ratio was 2) were charged into a three-necked, $500 \mathrm{~mL}$ flask equipped with a condenser, a thermometer, a teflon stirrer and the reaction temperature was maintained at $45-50^{\circ} \mathrm{C}$ for $30 \mathrm{~min}$. Then the temperature was gradually raised to around $80^{\circ} \mathrm{C}$, and $160 \mathrm{~g}$ of Chinese fir liquid was then added during a period of 50min. After all of the Chinese fir liquid had been infused, the reaction temperature was set at $92 \pm 2{ }^{\circ} \mathrm{C}$ immediately and maintained until the GardnerHoldt viscosity reached $500 \pm 20 \mathrm{mPas}\left(20 \pm 2^{\circ} \mathrm{C}\right)$. The viscosity measurements were carried out at 5 -min intervals. The finished adhesive was cooled to room temperature and kept in the refrigerator for use. About 250g of each adhesive sample was prepared. The PF resin was prepared as control sample. The solid content, free formaldehyde content and free phenol content of prepared adhesives were determined according to the China Industry Standard (GB/T 14074-2006).

\section{Resin solid content}

The percent of resin solid content is calculated by the following equation.

$$
S(\%)=\frac{S_{1}}{S_{0}} \times 100
$$

where "S" was the percent of resin solid content and " $S_{0}$ " and " $S_{1}$ " were the weight of the resin before and after dried, respectively. 


\section{Free formaldehyde content}

The free formaldehyde content of the prepared resins was determined by the hydroxylamine hydrochloride method. Accurately weighed about 0,003 or $0,005 \mathrm{~g}$ of resin sample was transferred into $250 \mathrm{~mL}$ beaker and dissolved in $50 \mathrm{~mL}$ methyl alcohol or $50 \mathrm{ml} 75 \%$ isopropyl alcohol. Simultaneously, the $\mathrm{pH}$ value of the solution was adjusted to 3,5 by adding $1 \mathrm{~N}$ hydrochloric acid solution. $25 \mathrm{~mL}$ of $10 \%$ hydroxylamine hydrochloride solution was added and stirred for $10 \mathrm{~min}$. Finally, the mixture solution was titrated with $0,1 \mathrm{~N}$ or $1 \mathrm{~N}$ sodium hydroxide solution. Free formaldehyde content was calculated by using following formula.

$$
\% \text { Free formaldehyde content }=\frac{3 c\left(V_{1}-V_{0}\right)}{m}
$$

where " $\mathrm{V}_{1}$ " and " $\mathrm{V}_{0}$ " are volumes of sodium hydroxide solution required in the titration for sample and blank, respectively. "c" is the exact normality of sodium hydroxide solution. " $\mathrm{m}$ " is weight of sample in $\mathrm{g}$.

\section{Free phenol content}

The percentage of free phenol was evaluated according to bromometry method. Accurately weighed about $0,002 \mathrm{~g}$ of resin sample was taken in $1000 \mathrm{~mL}$ round-bottomed flask. To that $100 \mathrm{~mL}$ distilled water was added and the $\mathrm{pH}$ value of the solution was adjusted to 4 by $20 \%$ hydrochloric acid solution. Then steam distilled until the negative test for phenol with bromine water. The distillate was diluted to $1000 \mathrm{~mL}$ with double distilled water. An aliquot of $50 \mathrm{~mL}$ was taken in Erlenmeyer flask and $25 \mathrm{~mL}$ of $0,1 \mathrm{~N}$ bromate-bromide solution and $5 \mathrm{~mL}$ concentrated $\mathrm{HCl}$ was added. The flask was then closed and kept in dark for $15 \mathrm{~min}$. After that $0,0018 \mathrm{~g}$ potassium iodide was added and kept in dark for another $10 \mathrm{~min}$. Finally, the mixed solution was titrated with $0,1 \mathrm{~N}$ sodium thiosulphate solution using starch as indicator. The free phenol was calculated by following formula

$$
\text { Phenol content }(\text { by weight })=\frac{\left(\mathrm{V}_{1}-\mathrm{V}_{2}\right) \times \mathrm{c} \times 0.01568 \times 1000}{\mathrm{~m} \times 50} \times 100 \%
$$

where " $\mathrm{V}_{1}$ " and " $\mathrm{V}_{2}$ " are the volumes of $0,1 \mathrm{~N}$ sodium thiosulphate solution required for blank and sample, respectively. " $\mathrm{m}$ " is the weight of sample in $\mathrm{g}$ and "c" is the exact normality of sodium thiosulphate solution.

\section{Viscosity measurements}

The viscosity of the Chinese fir-based adhesives and PF resins were measured using a Brookfield rotary viscometer with spindle at $20 \pm 2^{\circ} \mathrm{C}$. An average value of three replicate measurements was reported.

\section{Evaluation of plywood}

Eucalyptus veneers with dimensions of $320 \mathrm{~mm} \times 320 \mathrm{~mm} \times 2,1 \mathrm{~mm}$ were used to prepare 3-layer plywood panels. Chinese fir-based adhesive was applied to both sides of a veneer at a spread rate of $350 \mathrm{~g} / \mathrm{m}^{2}$ (for double bondlines). The adhesive-coated veneer was then stacked between two uncoated veneers with the grain directions of two adjacent veneers perpendicular to each other. Thereafter, the assembled veneers were pre-pressed (pressure, $1 \mathrm{MPa}$ ) at room temperature for $1 \mathrm{~h}$. After that, the prepressed veneers were hot-pressed at $120^{\circ} \mathrm{C}$ for $6 \mathrm{~min}$ at the same pressure of $1 \mathrm{MPa}$. Each resin obtained was used to prepare 3 piece of plywood. The specimens were maintained at $20 \pm 2^{\circ} \mathrm{C}$ and $45 \pm 5 \%$ relative humidity for 24 hours, sawn to get samples for the test of bonding strength and formaldehyde emission. A total of 48 specimens of $100 \times 25 \mathrm{~mm}$ ( 4 cycles' test, 12 specimens were prepared for each cycle) were cut from each panel for bond strength tests, according to JIS K6806-2003 standard. Ten specimens of $150 \times 50 \mathrm{~mm}$ were cut from panel to determine the formaldehyde emission according to JIS A1460-2003 standard. The formaldehyde emission was tested by a 120 -mm-diameter, 60 -mm-high crystallizing dish containing $300 \mathrm{~mL}$ of distilled water was placed in the bottom of a $240-\mathrm{mm}$-diameter desiccator with a 
capacity of $10 \pm 1 \mathrm{~L}$. Ten pieces of test specimens (with dimensions of $150 \times 50 \times 6 \mathrm{~mm}$ ) were clamped in a metal support, with no contact between specimens and allowed to stand on the perforate plate located over crystallizing dish in the desiccators at $20 \pm 2{ }^{\circ} \mathrm{C}$ for $24 \mathrm{~h}$. Formaldehyde emissions from the specimens were absorbed by the distilled water, which was subsequently used as the sample solution.

\section{Fourier Transform Infrared (FT-IR) Spectroscopy test}

The adhesive sample was placed in an oven at $160 \pm 2^{\circ} \mathrm{C}$ until a constant weight was obtained. FTIR spectra of both samples were performed in a Perkin Elmer model Spectrum V10 instrument. Each spectrum was recorded in a frequency range of $400-4000 \mathrm{~cm}^{-1}$ using potassium bromide (KBr) disc. The $\mathrm{KBr}$ was previously oven-dried at $300^{\circ} \mathrm{C}$ to reduce the interference of water.

\section{Differential Scanning Calorimetry (DSC) test}

DSC measurements were conducted on a NETZSCH 204 F1 differential scanning calorimeter. Dynamic scans were conducted in a temperature range of $30-250^{\circ} \mathrm{C}$, at constant heating rate of $10^{\circ} \mathrm{C} /$ min, under nitrogen atmosphere at a flux rate of $50 \mathrm{~mL} / \mathrm{min}$. For sample preparation, the sample was placed in an oven at $40 \pm 2{ }^{\circ} \mathrm{C}$ until a constant weight was obtained. About $0,006 \mathrm{~g}$ of the resin was used in an aluminum crucible of $40 \mu \mathrm{L}$ with a perforated lid.

\section{RESULTS AND DISCUSSION}

\section{Technical properties analysis}

All of the Chinese fir-based adhesives had the dark color with the specific smell. The resin solid content, free formaldehyde content and free phenol content were measured and the results are presented in table 2. 
Table 2. Resin solid content, free formaldehyde content and free phenol content.

\begin{tabular}{|c|c|c|c|}
\hline Adhesive ID & Solid content $(\%)$ & $\begin{array}{c}\text { Free formaldehyde } \\
\text { content }(\%)\end{array}$ & $\begin{array}{l}\text { Free phenol } \\
\text { content }(\%)\end{array}$ \\
\hline $60 / 40-2: 1$ & $46,16 \pm 0,06$ & $0,185 \pm 0,007$ & $0,048 \pm 0,0013$ \\
\hline $55 / 45-2: 1$ & $47,08 \pm 0,03$ & $0,258 \pm 0,003$ & $0,066 \pm 0,0019$ \\
\hline $50 / 50-2: 1$ & $48,71 \pm 0,11$ & $0,276 \pm 0,002$ & $0,081 \pm 0,0007$ \\
\hline $60 / 40-2,5: 1$ & $42,27 \pm 0,11$ & $0,368 \pm 0,002$ & $0,031 \pm 0,0011$ \\
\hline $55 / 45-2,5: 1$ & $44,17 \pm 0,03$ & $0,498 \pm 0,002$ & $0,062 \pm 0,0007$ \\
\hline $50 / 50-2,5: 1$ & $46,74 \pm 0,07$ & $0,693 \pm 0,003$ & $0,085 \pm 0,0010$ \\
\hline $60 / 40-3: 1$ & $40,78 \pm 0,16$ & $1,021 \pm 0,003$ & $0,018 \pm 0,0002$ \\
\hline $55 / 45-3: 1$ & $42,89 \pm 0,17$ & $1,724 \pm 0,001$ & $0,056 \pm 0,0005$ \\
\hline $50 / 50-3: 1$ & $45,41 \pm 0,03$ & $1,921 \pm 0,003$ & $0,070 \pm 0,0006$ \\
\hline $2: 1$ & $54,99 \pm 0,16$ & $0,355 \pm 0,002$ & $0,126 \pm 0,0006$ \\
\hline $2,5: 1$ & $49,48 \pm 0,12$ & $1,284 \pm 0,019$ & $0,098 \pm 0,0003$ \\
\hline $3: 1$ & $47,93 \pm 0,03$ & $4,241 \pm 0,015$ & $0,074 \pm 0,0006$ \\
\hline
\end{tabular}

Resin solid content is an important property for phenolic resin. Low solid content adhesive will eject out more water during the hot pressing, which could reduce the bonding strength of the plywood. As expected, the control PF resin adhesives have higher solid content than the Chinese fir-based adhesives at the same F/P molar ratio. The solid content of Chinese fir-based adhesives ranges from $40,78 \%$ to $48,71 \%$, which exceeded the minimum requirements of $35 \%$ in phenolic resin adhesive (Jin et al. 2010). With increasing the $\mathrm{CF} / \mathrm{PF}$ mass ratio and $\mathrm{F} / \mathrm{P}$ molar ratio, a decreasing solid content in Chinese fir-based adhesives was observed.

Free formaldehyde and free phenol are the components of toxicity in phenolic or aldehydic synthetic resin. In general, low toxic PF resin follows with poor bond strength, while great bonding strength is often accompanied with high toxicity. Results in table1 showed that the free formaldehyde and free phenol of the synthetic Chinese fir-based adhesives would decrease along with the increasing addition of Chinese fir liquid. With the $\mathrm{CF} / \mathrm{PF}$ rising from $50 / 50$ to $60 / 40$, the free formaldehyde content and free phenol content of the Chinese fir-based adhesives ( $\mathrm{F} / \mathrm{P}=2: 1$ ) decreased from $0,276 \%$ to $0,185 \%$ and $0,081 \%$ to $0,048 \%$, respectively, which were far less than those of control PF resin. The free formaldehyde and free phenol were similar to those of the Chinese fir-based adhesives with higher F/P molar ratios (Hassan et al. 2009). As known, the alkaline liquefaction of Chinese fir breaks down lignin, cellulose and hemicellulose. The lignin was further hydrolyzed to three main structural units of benzyl propane: guaiacyl (G), hydroxyl phenyl (H) and syringyl (S) (Moze 1999). H-type units have 2 reactive sites at C3 and C5 position in the ring, susceptible of reacting with formaldehyde, while in S-type units both $\mathrm{C} 3$ and $\mathrm{C} 5$ positions are linked to a methoxy group, resulting in low reactivity with formaldehyde. From this point of view, lignin 
with $\mathrm{H}$ groups as the principal structural units must be a priori more suitable for PF formulations, and the $\mathrm{G}$ groups take the second place. The units of $\mathrm{H}$ and $\mathrm{G}$ react with formaldehyde in alkaline medium producing H-hydroxymethyl and G-hydroxymethyl, the reaction formula is illustrated in equation (1) and equation (2). Then the H-hydroxymethyl and G-hydroxymethyl occured the dehydrolytic condensation and form the cross-linked structure. When exposed at high temperature $\left(200^{\circ} \mathrm{C} \sim 220^{\circ} \mathrm{C}\right)$, cellulose and hemicellulose were firstly degraded through hydrolysis path to oligosaccharide and then converted in alkaline pathway to glucose (Yin et al. 2011). And the glucose then degraded in alkaline conditions to generate carboxylic acid so that reduce the $\mathrm{pH}$ value of the solution. As soon as the $\mathrm{pH}$ value less than 7,0 the glucose transformed to hydroxymethyl furfural (HMF) through diverse elimination reactions. Due to the similar chemical property to formaldehyde, the phenol was consumed by the condensation reaction of the HMF, which occurred at three reactive sites. Hence, the use of an optimum amount of formaldehyde and phenol can form and improve the chance of Chinese fir liquid's incorporation into the PF resin structures.

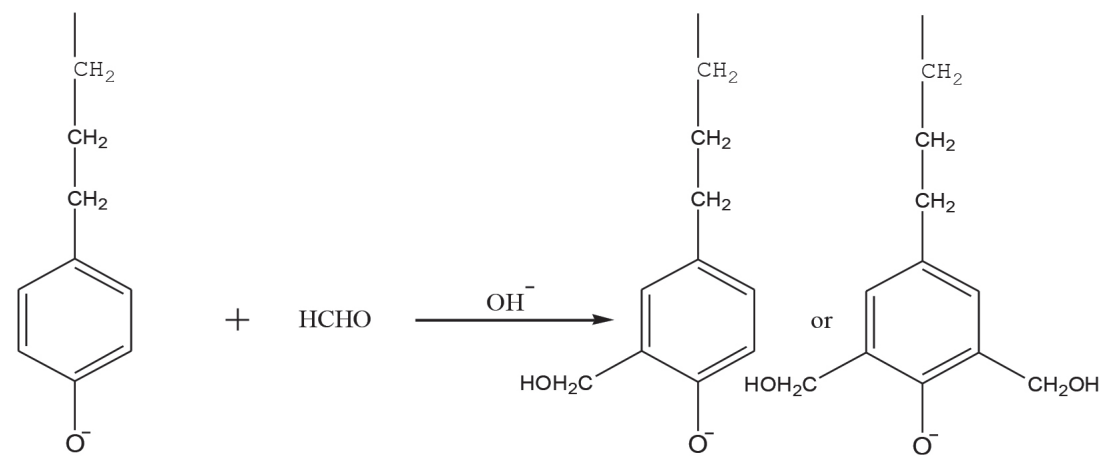

P-hydroxy group reaction with formaldehyde

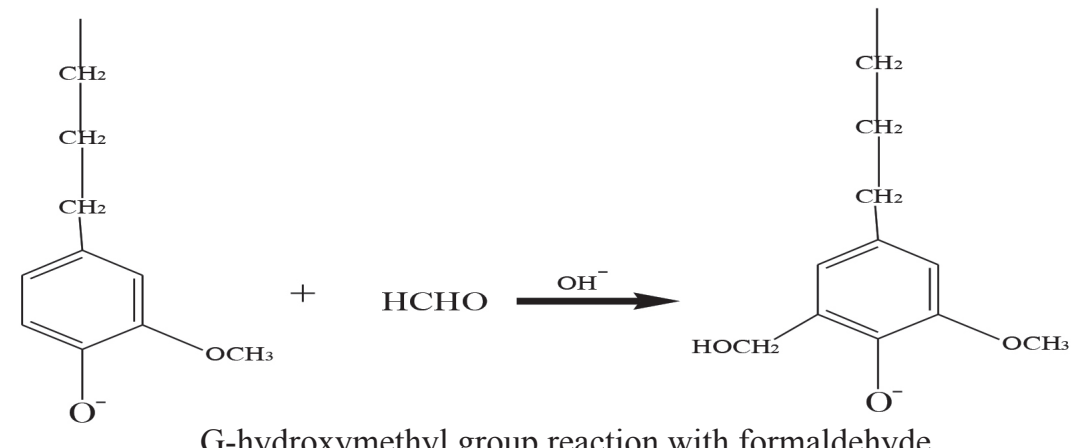

G-hydroxymethyl group reaction with formaldehyde 


\section{Bonding properties analysis}

Table 3. Boiling bond strength of plywood on different test conditions.

\begin{tabular}{ccccc}
\hline Adhesive ID & $\begin{array}{c}28-\mathrm{h}^{\mathrm{a}} \text { boiling test } \\
\text { (wood failure) }\end{array}$ & $\begin{array}{c}52-\mathrm{h}^{\mathrm{b}} \text { boiling test } \\
\text { (wood failure) }\end{array}$ & $\begin{array}{c}76-\mathrm{h}^{\mathrm{c}} \text { boiling test } \\
\text { (wood failure) }\end{array}$ & $\begin{array}{c}100-\mathrm{h}^{\mathrm{d}} \text { boiling test } \\
\text { (wood failure) }\end{array}$ \\
\hline $60 / 40-2: 1$ & $1,14 \pm 0,03^{\mathrm{e}}\left(60^{\mathrm{f}}\right)$ & $1,01 \pm 0,03(50)$ & $0,89 \pm 0,05(30)$ & $0,41 \pm 0,05(10)$ \\
$55 / 45-2: 1$ & $1,32 \pm 0,08(80)$ & $1,22 \pm 0,08(75)$ & $1,02 \pm 0,03(55)$ & $0,85 \pm 0,04(25)$ \\
$50 / 50-2: 1$ & $1,51 \pm 0,06(90)$ & $1,35 \pm 0,03(70)$ & $1,23 \pm 0,05(60)$ & $1,08 \pm 0,03(50)$ \\
$60 / 40-2,5: 1$ & $0,96 \pm 0,06(60)$ & $0,72 \pm 0,03(20)$ & $0,33 \pm 0,04(0)$ & failure \\
$55 / 45-2,5: 1$ & $1,42 \pm 0,04(90)$ & $1,11 \pm 0,05(60)$ & $0,93 \pm 0,04(45)$ & $0,71 \pm 0,03(30)$ \\
$50 / 50-2,5: 1$ & $1,38 \pm 0,05(85)$ & $1,14 \pm 0,05(70)$ & $0,95 \pm 0,04(50)$ & $0,77 \pm 0,05(30)$ \\
$60 / 40-3: 1$ & $0,56 \pm 0,04(30)$ & failure & failure & failure \\
$55 / 45-3: 1$ & $0,84 \pm 0,04(50)$ & $0,46 \pm 0,04(10)$ & failure & failure \\
$50 / 50-3: 1$ & $1,00 \pm 0,07(60)$ & $0,82 \pm 0,04(50)$ & $0,71 \pm 0,03(30)$ & failure \\
$2: 1$ & $1,54 \pm 0,05(90)$ & $1,28 \pm 0,05(75)$ & $1,12 \pm 0,05(70)$ & $0,91 \pm 0,05(60)$ \\
$2,5: 1$ & $1,48 \pm 0,05(90)$ & $1,11 \pm 0,04(80)$ & $0,98 \pm 0,05(60)$ & $0,78 \pm 0,05(40)$ \\
$3: 1$ & $1,34 \pm 0,05(80)$ & $1,01 \pm 0,06(60)$ & $0,89 \pm 0,04(30)$ & failure \\
\hline & & & &
\end{tabular}

a $4 \mathrm{~h}$ in boiling water, $20 \mathrm{~h}$ in $63 \pm 3^{\circ} \mathrm{C}$ oven, $4 \mathrm{~h}$ in boiling water;

b $4 \mathrm{~h}$ in boiling water, $20 \mathrm{~h}$ in $63 \pm 3^{\circ} \mathrm{C}$ oven, $4 \mathrm{~h}$ in boiling water, $20 \mathrm{~h}$ in $63 \pm 3^{\circ} \mathrm{C}$ oven, $4 \mathrm{~h}$ in boiling water;

${ }^{\mathrm{c}} 4 \mathrm{~h}$ in boiling water, $20 \mathrm{~h}$ in $63 \pm 3^{\circ} \mathrm{C}$ oven, $4 \mathrm{~h}$ in boiling water, $20 \mathrm{~h}$ in $63 \pm 3^{\circ} \mathrm{C}$ oven, $4 \mathrm{~h}$ in boiling water, $20 \mathrm{~h}$ in $63 \pm 3^{\circ} \mathrm{C}$ oven, $4 \mathrm{~h}$ in boiling water;

d $4 \mathrm{~h}$ in boiling water, $20 \mathrm{~h}$ in $63 \pm 3^{\circ} \mathrm{C}$ oven, $4 \mathrm{~h}$ in boiling water, $20 \mathrm{~h}$ in $63 \pm 3^{\circ} \mathrm{C}$ oven, $4 \mathrm{~h}$ in boiling water, $20 \mathrm{~h}$ in $63 \pm 3^{\circ} \mathrm{C}$ oven, $4 \mathrm{~h}$ in boiling water, $20 \mathrm{~h}$ in $63 \pm 3^{\circ} \mathrm{C}$ oven, $4 \mathrm{~h}$ in boiling water;

e unit: MPa; f unit: \%. 
In order to enhance the bonding strength and boiling water resistance, formaldehyde and phenol were used to co-polymerize with alkaline Chinese fir liquid. The boiling bonding strength and wood failure were evaluated for plywood panels bonded with various Chinese fir-based adhesives and control PF resin adhesives. The test results are presented in table 3 . To verify the boiling water resistance and durability, the test specimens were measured on more rigor conditions after the plywood specimens had been subjected to a 54-h, 76-h and 100-h cycle. The results showed that all the 28-h boilingdrying-boiling tests for panels prepared with Chinese fir-based adhesives with $\mathrm{F} / \mathrm{P}=2$ exceeded $1,1 \mathrm{MPa}$ without evaluating the wood failure. This means that the Chinese fir-based adhesives formulation with $\mathrm{F} / \mathrm{P}=2$ exceed the requirement set by JIS K6806-2003 for application in exterior use. The results in the 52 -h boiling cycle test were also outstanding because the values were greater than $1.0 \mathrm{MPa}$ as before. Moreover, the 76-h boiling tests for panels prepared with the formulation of 50/50-2:1 and the 55/45-2:1 were 1,23 $\pm 0,05 \mathrm{MPa}$ and 1,02 $\pm 0,03 \mathrm{MPa}$, which still met the JIS K6806-2003 standard 0,98MPa. In the 100-h boiling cycle procedure, nothing but the evaluated value of the adhesive 50/50-2:1 exceeded the minimum requirement of JIS K6806-2003 standard. All the results above indicated that the Chinese fir-based adhesive had wonderful water resistance and durability, especially the adhesive 50/50-2:1.

The boiling bonding strength and wood failure of adhesive 50/50-2:1 for the 52-h cycle test, 76-h cycle test, and 100-h cycle test were $1,35 \pm 0,03 \mathrm{MPa}(70 \%), 1,23 \pm 0,05 \mathrm{MPa}(60 \%)$, and $1,08 \pm 0,03 \mathrm{MPa}$ $(50 \%)$ apparently, while the results for the control PF were $1,28 \pm 0,05 \mathrm{MPa}(65 \%), 1,12 \pm 0,05 \mathrm{MPa}(50 \%)$, and $0,91 \pm 0,05 \mathrm{MPa}(40 \%)$ under the same test conditions. This could be attributed to the higher reactivity of the liquefaction, or more active sites on the liquefaction using a catalyst of $\mathrm{NaOH}$. More active sites could react with more formaldehyde and phenol, thereby resulting in a higher crosslinking density of the adhesive after curing. That is why the adhesive 50/50-2:1 had better boiling water resistance and durability than the control PF resin. And it is important that the Chinese fir liquid is not used as filler but raw material reacted with formaldehyde and phenol.

\section{Formaldehyde emission}

Formaldehyde emission of specimens was measured by 24-h desiccator method. figure 2 shows the formaldehyde emission results for the various specimens. Each specimen was tested twice and good repeatability of results was obtained with a maximum relative standard deviation of less than $2 \%$. The formaldehyde emission of all the panels approached to the value of $\mathrm{E}_{0}$ specified in the JIS A1460-2003 standard (the value is less than $0,5 \mathrm{mg} / \mathrm{L}$ ) except the panel bonded with the control PF resin with the F/P ratio of 3:1. The quantity of formaldehyde emission of plywood bonded with Chinese fir-based adhesives decreased with the increasing $\mathrm{CF} / \mathrm{PF}$ ratio as shown in figure 2 . It can be seen that the sample in the group of $\mathrm{F} / \mathrm{P}=3: 1$, with a $\mathrm{CF} / \mathrm{PF}$ ratio of $60 / 40$, achieving the lowest formaldehyde emission value of $0,102 \mathrm{mg} / \mathrm{L}$, which was only $1 / 5$ of the $\mathrm{E}_{0}$ specified value. Panels bonded with the Chinese fir-based adhesives emitted less formaldehyde than panels bonded with the control PF resin adhesive by $50-80 \%$. This may be due to the depolymerization products of lignin maintaining their aromatic character and high reactivity, which act as radical scavengers and can therefore readily react with free formaldehyde in the mixture, during crosslinking process (Kunaver et al. 2010). 


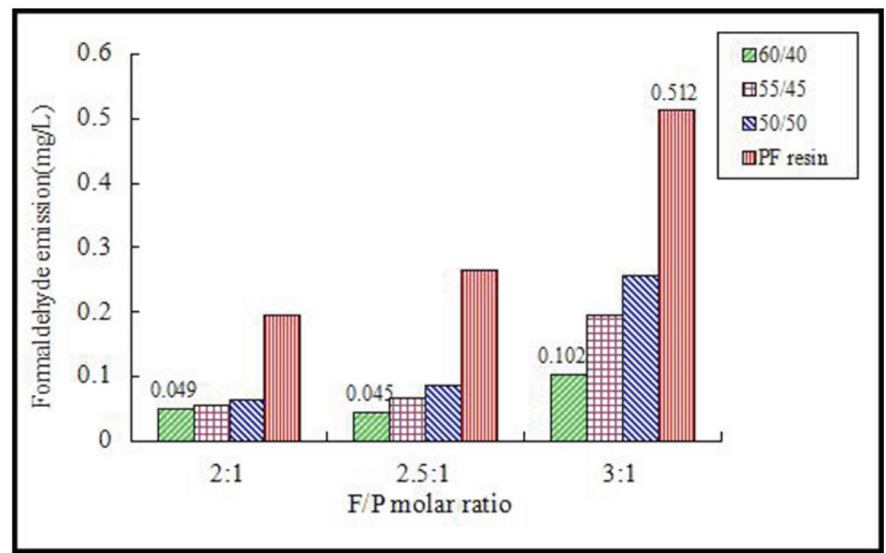

Figure 2. Formaldehyde emission of plywood.

\section{FT-IR analysis}

The spectra of the Chinese fir-based adhesive and control PF resin adhesive are presented in figure 3, figure 4 and figure 5. (Hirokazu et al. 2011, Kadla et al. 2002, Poljanšek and Krajnc 2005).

As shown in figure 3, the Chinese fir-based adhesive showed a similar FT-IR absorbance to that of the control PF resin adhesive. The band at $3420 \mathrm{~cm}^{-1}$ in Chinese fir-based adhesive and the band at $3416 \mathrm{~cm}^{-1}$ in control PF resin are assigned to aromatic and aliphatic $\mathrm{OH}$ groups while the bands at 2948, 2850 and $1460 \mathrm{~cm}^{-1}$ in Chinese fir-based adhesive and the bands at 2946, 2845 and $1458 \mathrm{~cm}^{-1}$ in control $\mathrm{PF}$ resin are related to the $\mathrm{C}-\mathrm{H}$ vibration of $\mathrm{CH}_{2}$ and $\mathrm{CH}_{3}$ groups. They are typical vibrations of methoxyl groups. However, with the incorporation of wood components, the FT-IR spectra of the Chinese fir-based adhesive contained some different bands compared with that of the control PF resin. The major difference in the spectra between the Chinese fir-based adhesive and control resin adhesive is the absorbance in the carbonyl region. As shown in figure 4, the peaks at 1733,1698 , and $1652 \mathrm{~cm}^{-1}$ in Chinese fir-based adhesive are ascribed to the ester carbonyl stretch, aryl ketone or aldehyde carbonyl stretch, and the di-substituted alkene $\mathrm{C}=\mathrm{CH}_{2}$, respectively. However, the control PF resin showed no absorbance in this region as expected. Furthermore, the spectra of the Chinese fir-based adhesive also showed two weak bands at 1473 and $879 \mathrm{~cm}^{-1}$ caused by tetra substituted $(1,2,4$, and 6$)$ ring which did not occur in the spectra of control resin. It implies that the existence of some lignin fragments, most of which are tetra substituted aromatic rings in the Chinese fir-based adhesive. The other difference in the spectra between the Chinese fir-based adhesive and control resin occurred at $1077 \mathrm{~cm}^{-1}$ (figure 5), with the band attributed to the ether linkage on the furan ring and the band at $1048 \mathrm{~cm}^{-1}$ attributed to the single bond $\mathrm{C}-\mathrm{O}-\mathrm{C}$ stretch with $-\mathrm{CH}_{2} \mathrm{OH}$ vibrations. Based on the above discussion, the bands at 1077 , $1048 \mathrm{~cm}^{-1}$ are associated with the 5-HMF that reacted with phenol during the polycondensation reaction. 


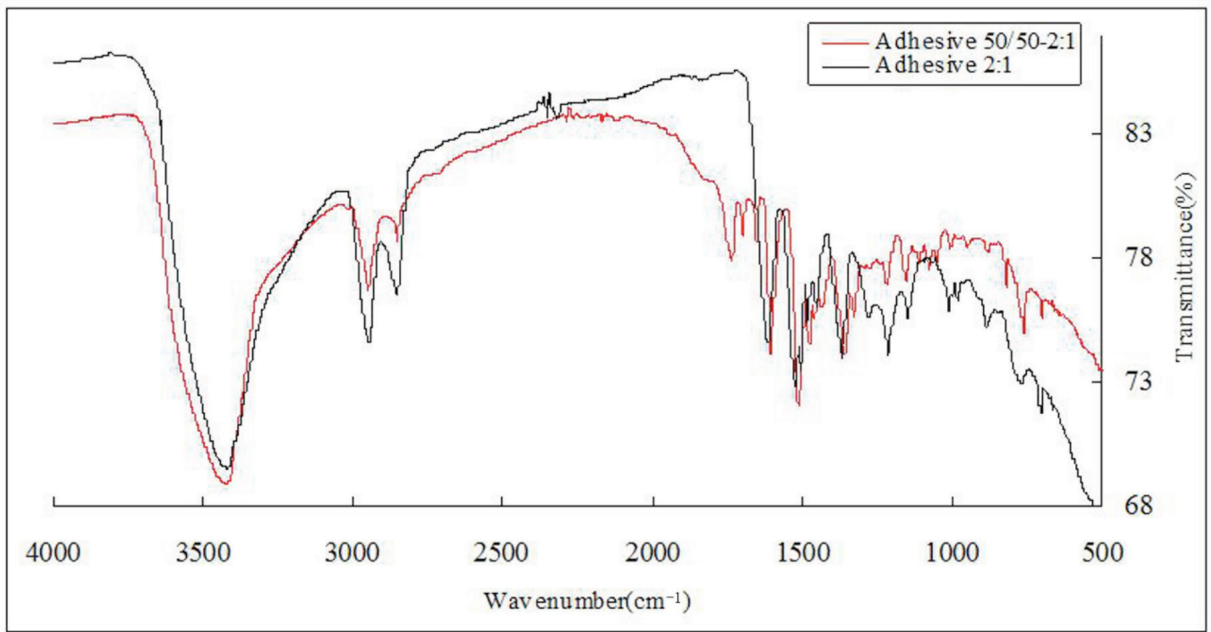

Figure 3. FT-IR spectra of adhesive 50/50-2:1 and adhesive 2:1.

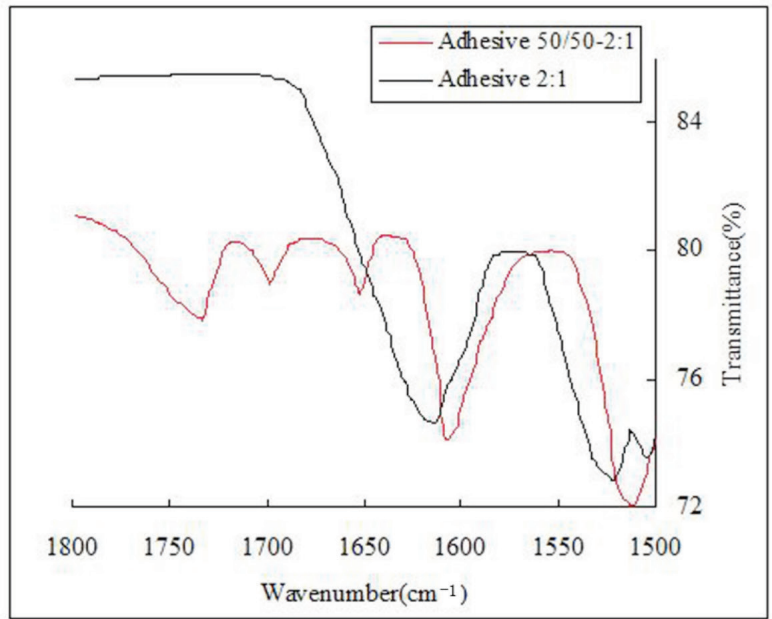

Figure 4. FT-IR spectra of adhesive 50/50-2:1 and adhesive 2:1.

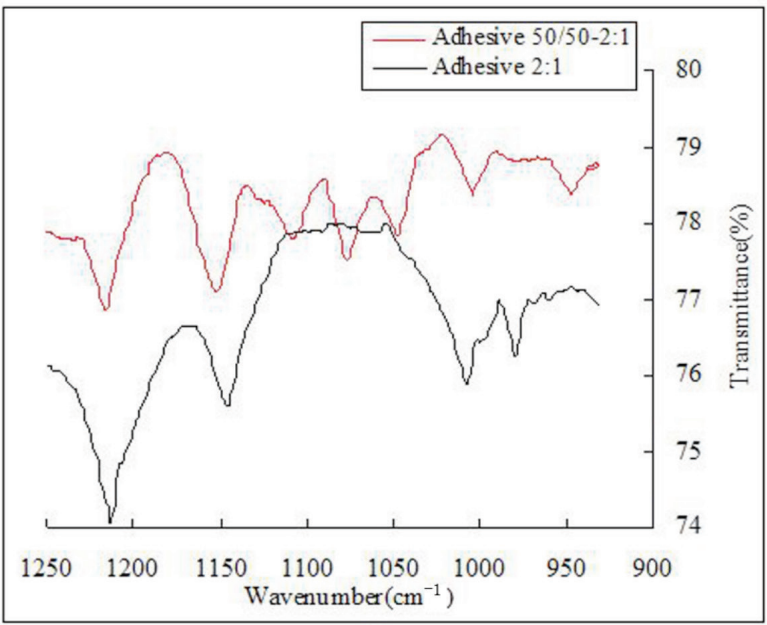

Figure 5. FT-IR spectra of adhesive 50/50-2:1 and adhesive 2:1. 


\section{DSC analysis}

The isothermal DSC curves at a heating rate of $10^{\circ} \mathrm{C} / \mathrm{min}$ of Chinese fir-based adhesives and control PF resin adhesives are shown in figure 6 and figure 7. The results obtained are summarized in table 4 containing onset temperature, peak temperature and $\Delta \mathrm{H}$.

Table 4. The onset temperature, peak temperature and $\Delta \mathrm{H}$ of the adhesives.

\begin{tabular}{ccccc}
\hline Adhesive ID & $\begin{array}{c}\text { Onset temperature } \\
\left({ }^{\circ} \mathrm{C}\right)\end{array}$ & $\begin{array}{c}\text { Peak 1 } \\
\text { temperature }\left({ }^{\circ} \mathrm{C}\right)\end{array}$ & $\begin{array}{c}\text { Peak 2 } \\
\text { Temperature }\left({ }^{\circ} \mathrm{C}\right)\end{array}$ & $\begin{array}{c}\Delta \mathrm{H} \\
(\mathrm{mJ} / \mathrm{mg})\end{array}$ \\
\hline $1: 2$ & 114,7 & $/$ & 141,8 & 96,4 \\
$(70 / 30)-1: 2$ & 116,4 & $/$ & 149,3 & 68,7 \\
$(60 / 40)-1: 2$ & 115,6 & $/$ & 147,5 & 72,9 \\
$(50 / 50)-1: 2$ & 114,6 & $/$ & 146,1 & 78,3 \\
$(50 / 50)-1: 2,5$ & 112,5 & 142,1 & 155,0 & 89,2 \\
$(50 / 50)-1: 3$ & 111,4 & 144,8 & 159,5 & 101,5 \\
\hline
\end{tabular}

Figure 6 and figure 7 show that the resin samples gave a single or two exothermic peaks in the range of $141,4-157,5^{\circ} \mathrm{C}$. Both of the exotherms obtained in the resin systems were attributable to the curing reaction. According to the previous research (Christiansen and Gollob 1985), the lower exothermic peak in the range of $141,4-144,8^{\circ} \mathrm{C}$ has been attributed to the addition reaction of free formaldehyde to phenolic ring, and the upper exothermic peak in the range of $143,8-157,5^{\circ} \mathrm{C}$ was associated with the chain-building condensation reactions, involving hydroxymethyl groups attached to various phenolic species. The appearance of single exothermic peak is mainly due to the F/P molar ratio below 2,3 that resulted in the overlapping of exothermic signals, two well-separated exothermic peaks are revealed when the F/P molar ratio was larger than 2,3 (Holopainen et al. 1997).

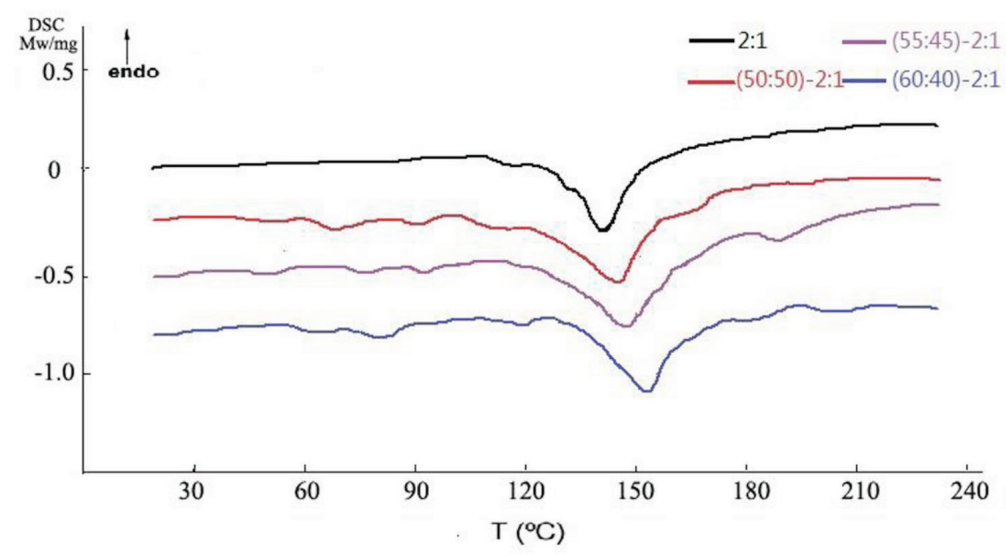

Figure 6. DSC curves of adhesive at $\mathrm{F} / \mathrm{P}=2$. 
Figure 6 shows the DSC curves of the Chinese fir-based adhesives $(\mathrm{F} / \mathrm{P}=2)$ with a $\mathrm{CF} / \mathrm{PF}$ ratio of $50 / 50,55 / 45$ and $60 / 40$, respectively. As the data listed in table 4 , the extrapolated onset temperatures for the Chinese fir-based adhesives at $\mathrm{F} / \mathrm{P}=2$ were found to be $114,6^{\circ} \mathrm{C}, 115,6^{\circ} \mathrm{C}$ and $116,4^{\circ} \mathrm{C}$, respectively. It was close to the control PF resin adhesive of the same molar ratio, but slightly higher than the Chinese fir-based adhesive with larger F/P molar ratio. This indicated that with larger F/P molar ratio Chinese fir-based adhesives were more reactive at the low temperatures. As far as the effect of CF-to-PF ratio is concerned, it can be seen from figure 6 that the onset temperature and peak temperature of the Chinese fir-based adhesives shifted to higher temperatures with an increase of CF/PF mass ratio. However, the $\Delta \mathrm{Hs}$ of cure were significantly reduced. Compared with the control PF resin at the same molar ratio, the Chinese fir-based adhesives had higher peak temperature and lower $\Delta \mathrm{H}$. This is probably because lignin has less free ring positions than phenol and more steric impediments that delays the hardening of Chinese fir-based adhesives. Furthermore, lignin introduces an extra amount of methylol groups similar to those produced by formaldehyde during curing, what will act in the opposite way.

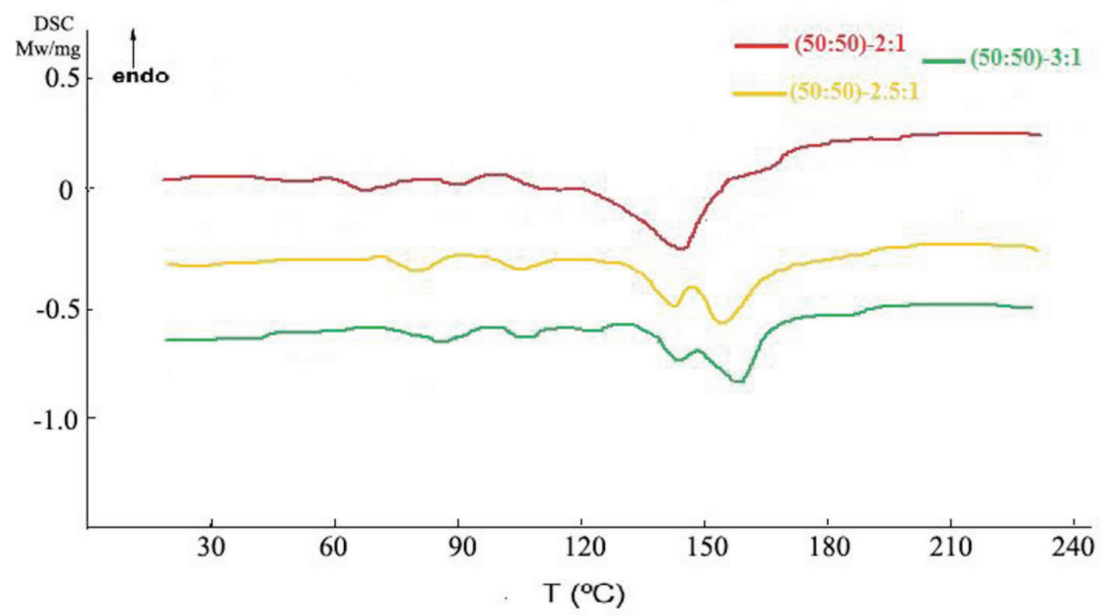

Figure 7. DSC curves of Chinese fir-based adhesive with $\mathrm{CF} / \mathrm{PF}=50 / 50$.

Figure 7 shows the DSC curves of the Chinese fir-based adhesives $(\mathrm{CF} / \mathrm{PF}=50)$ with $\mathrm{F} / \mathrm{P}$ molar ratios of 2:1, 2,5:1 and 3:1. Due to the F/P molar ratio lower than 2,3, the DSC curve of the Chinese fir-based adhesive $(\mathrm{F} / \mathrm{P}=2: 1)$ reveals only a single exothermic at the peak temperature of $146,1^{\circ} \mathrm{C}$. The DSC curves of the Chinese fir-based adhesives $(\mathrm{CF} / \mathrm{PF}=50)$ with a $\mathrm{F} / \mathrm{P}$ molar ratio of 2,5:1 and 3:1 manifested that the curing behavior is completed in two steps which are signified by two exothermic curves. The peak temperature for the Chinese fir-based adhesive with a molar ratio of $2,5: 1$ was $142,1^{\circ} \mathrm{C}$ and $155^{\circ} \mathrm{C}$, respectively. And they were $144,8^{\circ} \mathrm{C}$ and $157,2^{\circ} \mathrm{C}$ for the Chinese fir-based adhesive with a molar ratio of $3: 1$. This implies that the Chinese fir-based resins with larger $\mathrm{F} / \mathrm{P}$ molar ratio needed a higher temperature for completely curing. The $\Delta \mathrm{H}$ in table 4 suggested that the Chinese fir-based adhesive $(\mathrm{CF} / \mathrm{PF}=50 / 50$ and $\mathrm{F} / \mathrm{P}=3: 1$ ) reacted more strongly than the other resins due to the larger $\Delta \mathrm{H}$ released during curing. 


\section{CONCLUSIONS}

The alkaline Chinese fir (Cunninghamia lanceolata) liquid is proved to be useful raw material for plywood adhesives. The process of liquefaction is easy to carry out which make it possible for industrial production. The synthetic Chinese fir-based adhesives exhibit excellent improvements in free formaldehyde content and free phenol content. More important, the properties of plywood glued with the Chinese fir-based adhesives $(\mathrm{CF} / \mathrm{PF}=50 / 50, \mathrm{~F} / \mathrm{P}=2: 1)$ after 100 -h boiling drying cycle still meet the requirement of the JIS K6806-2003 standard in exterior application and the formaldehyde emission is only $0,074 \mathrm{mg} / \mathrm{L}$ which is much less than that of the $\mathrm{E}_{0}$ specified in the JIS A1460-2003 standard (the value is less than $0,5 \mathrm{mg} / \mathrm{L}$ ). In addition, the cost of this adhesive appears much lower than that of the synthetic phenolic resins traditional used for wood adhesives. Hence, we can predicate that the Chinese fir-based adhesive will not only help reduce the polymer industry's dependence on petro-chemical industry but also be applied for industrial production.

\section{ACKNOWLEDGEMENTS}

Laboratory of Wood Science and Engineering, South China Agriculture University (SCAU) has been greatly acknowledged for financial support and supplied raw materials.

\section{REFERENCES}

Bisanda, E.T.N.; Ogola, W.O.; Tesha, J.V. 2003. Characterisation of tannin resin blends for particle board applications. Cement and Concrete Composites 25(6): 593-598.

Chen, H.; Zhang, Y.; Xie, S. 2012. Selective liquefaction of wheat straw in phenol and its fractionation. Applied Biochemistry and Biotechnology 167(2): 250-258.

Christiansen, A.W.; Gollob, L. 1985. Differential scanning calorimetry of phenol-formaldehyde resols. Journal of Applied Polymer Science 30(6): 2279-2289.

Hajime, K.; Yuki, A.; Masayuki, N.; Akira, F.; Satoshi, M.; Hirofumi, N. 2011. Synthesis of Epoxy Resins from Alcohol-Liquefied Wood and the Mechanical Properties of the Cured Resins. Journal of Applied Polymer Science 120(2): 745-751.

Hassan, E.B.; Kim, M.; Wan, H. 2009. Phenol-Formaldehyde-Type resins made from PhenolLiquefied wood for the bonding of particleboard. Journal of Applied Polymer Science 112(3): 1436-1443.

Hirokazu, K.; Yukiko, I.; Tasuku, K.; Yuto, H.; Paresh, D.; Koji, K.; Kenji, H.; Atsushi, F. 2011. Synthesis of sugar alcohols by hydrolytic hydrogenation of cellulose over supported metal catalysts. Green Chemistry 13(2): 326-333.

Holopainen, T.; Alvila, L.; Rainio, J.; Pakkanen, T.T. 1997. Phenol-formaldehyde resol resins studied by $13 \mathrm{C}$ NMR spectroscopy, gel permation chromatography and differential scanning calorimetry. Journal of Applied Polymer Science 66(6): 1183-1193.

Jin, Y.; Cheng, X.; Zheng, Z. 2010. Preparation and characterization of phenol-formaldehyde adhesives modified with enzymatic hydrolysis lignin. Bioresource Technology 101(6): 2046-2048.

Joseph, B.; Ronald, R. 2009. Simple chemical transformation of lignocellulosic biomass into furans for fuels and chemicals. Journal of the American Chemical Society 131(5): 1979-1985. 
Kadla, JF.; Kubo, S.; Venditti, RA.; Gilbert, RD.; 2002. Novel hollow core fibers prepared from lignin polypropylene blends. Journal of Applied Polymer Science 85(6): 1353-1355.

Kouisni, L.; Fang, Y.; Paleologou, M.; Behzad, A.; Jalal, H.; Zhang, Y.; Wang, X.; 2011. Kraft lignin recovery and its use in the preparation of lignin-based phenol formaldehyde resins for plywood. Cellulose Chemistry and Technology 45(7-8): 515-520.

Kunaver, M.; Medved, S.; Cuk, N.; Jasiukaitytė, E.; Poljanšek, I.; Strnad, Tatjana. 2010. Application of liquefied wood as a new particle board adhesive system. Bioresource Technology 101(4): 1361-1368.

Lee, W.; Yu, C.; Chang, K.; Huang, Y.; Chang, C.; Liu, C. 2011. Spherical PF resin beads prepared from phenol-liquefied Bambusa dolichoclada with suspension polymerization. Holzforschung 65(2): 163169.

Liu, M.; Wang, H.; Han, J.; Niu, Y. 2012. Enhanced hydrogenolysis conversion of cellulose to C2-C3 polyols via alkaline pretreatment. Carbohydrate Polymers 89(2): 607-612.

Moubarik, A.; Pizzi, A.; Allal, A.; Charrier, F.; Charrier, B. 2009. Cornstarch and tannin in phenolformaldehyde resins for plywood production. Industrial Crops and Products 30(2): 188-193.

Moze, A. 1999. Graft Copolymerization of magnefite lignin with acrylamide and acylic acid monomers. Cellulose Chemistry and Technology 33(5): 415-422.

Niu, M.; Zhao, G.; Hakki, A. 2011. Thermogravimetric studies on condensed wood residues in polyhydric alcohols liquefaction. BioResources 6(1): 615-630.

Papadopoulou, E.; Chrissafis, K. 2011. Thermal study of phenol-formaldehyde resin modified with cashew nut shell liquid. Thermochimica Acta 512(1-2): 105-109.

Poljanšek, I.; Krajnc, M. 2005. Characterization of Phenol-Formaldehyde Prepolymer Resins by In Line FT-IR Spectroscopy. Acta Chimica Slovenica 52(3): 238-244.

Ruesch, M.; Klaas, G.; Schoene, H. 2009. Direct, high-yield conversions of cellulose into biofuel and platform chemicals-on the way to a sustainable biobased economy. ChemSusChem 2(2): 127-128.

Wang, M.; Leitch, M.; Xu,C. 2009. Synthesis of phenolic resol resins using cornstalk-derived bio-oil produced by direct liquefaction in hot-compressed phenol-water. Journal of Industrial and Engineering Chemistry 15(6): 870-75.

Wang, W.; Zhao, Z.; Gao, Z.; Guo, M. 2012. Water-resistant whey protein based wood adhesive modified by post-treated phenol-formaldehyde oligomers (PFO). BioResources 7(2): 1972-1983.

Yang, I.; Ahn, S.; Choi, I.; Kim, H.; Oh, S. 2009. Adhesives formulated with chemically modified okara and phenol-resorcinol-formaldehyde for bonding fancy veneer onto high-density fiberboard. Journal of Industrial and Engineering Chemistry 15(3): 398-402.

Yin, S.; Anil, K.M.; Tan, Z. 2011. Alkaline hydrothermal conversion of cellulose to bio-oil: Influence of alkalinity on reaction pathway change. Bioresource Technology 102(11): 6605-6610.

Yin, S.; Dolan, R.; Harris, M.; Tan, Z. 2010. Subcritical hydrothermal liquefaction of cattle manure to bio-oil: Effects of conversion parameters on bio-oil yield and characterization of bio-oil. Bioresource Technology 101(10): 3657-3664. 